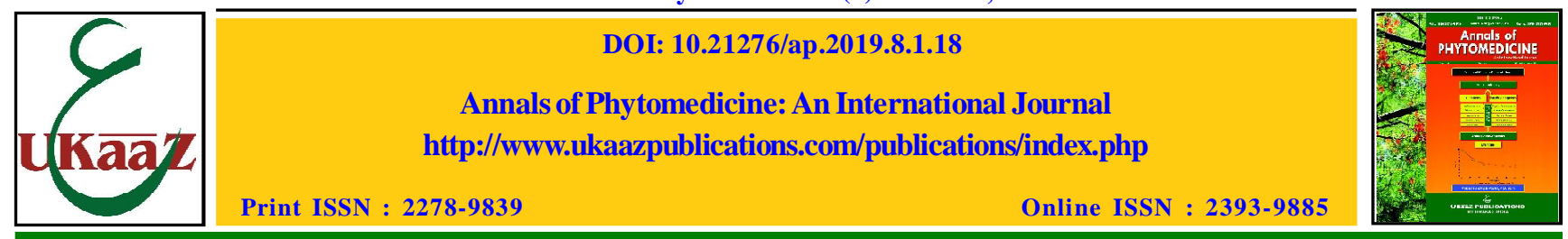

Original article

\title{
Phytochemical and antimicrobial efficacy of in vivo and in vitro tissues of Aegle marmelos (L.) Corrêa
}

\author{
P. Priyadharshini, Ashok Raj* and Rekha R. Warrier* \\ Institute of Forest Genetics and Tree Breeding (IFGTB), P.B.No. 1061, R.S. Puram, Coimbatore-641002, \\ Tamil Nadu, India \\ *Department of Agricultural Microbiology, Tamil Nadu Agricultural University, Coimbatore-641003, \\ Tamil Nadu, India
}

Received January 5, 2019: Revised February 25, 2019: Accepted February 27, 2019: Published online June 30,2019

\begin{abstract}
A study was conducted with an aim to test the antimicrobial potential of in vivo and in vitro derived callus of Aegle marrmelos (L.) Corrêa against 12 phytopathogens, 5 benefical microbes and 4 clinical human pathogens. Antimicrobial efficacy of the chloroform and methanol extract of A. marmelos roots tested by well diffusion test showed effective reduction of growth of test pathogens. Among the phytopathogens tested, growth of Alternaria helianthi and Sclerotium rolfsi were inhibited. The chloroform extract of calli of A. marmelos showed the maximum antimicrobial activity $(94.45 \%)$ with an MIC of $2.0 \mu 1$. In clinical pathogens, methanol extract of the root bark showed high inhibition of E.coli over other organisms. The callus derived extracts showed similar response, however, Klebsiella pneumonia responded better to the callus extracts. The efficacy of the extracts derived from callus indicates their functional role in the chemical defence against microbial invasion. The present study suggests the possibility of using in vitro cultures for production of medicinally important bioactive compounds.
\end{abstract}

Keywords: Callus, bioefficacy, clinical pathogens, phytopathogens, bael, antimicrobial

\section{Introduction}

The World Health Organization (WHO) estimates the demand for medicinal plants at approximately US $\$ 14$ billion per year. This is likely to increase to more than US $\$ 5$ trillion in 2050 (Kala et al., 2006). Export market for herbal medicines is growing faster than the Indian domestic market. There is a consistent demand for more than 500 species both in the domestic and international markets. To meet this demand, rampant harvest of raw material from the wild is on. It is mostly as a destructive harvest, resulting in reduction in the genetic stocks. So, there is an urgency to manage and conserve these medicinal plant resources.

Conservation can be through management of wild populations and natural habitats. It can be propagated through seeds and cuttings. However, it takes time for the species to reach the harvestable age before it can be utilized for its pharmacologically active compounds. Modern pharmacopoeia contains at least 25\% drugs derived from plants and many others which are synthetic analogues built on prototype compounds isolated from plants (Manoharachary and Nagaraju, 2016). Application of biotechnological tools can help to biosynthesize the compounds in low quantities. Well-known examples are artemisinin, paclitaxel, podophyllotoxin and vincaalkaloids.

Secondary metabolite production can be manipulated by varying composition of the culture medium. This includes the types and

\footnotetext{
Author for correspondence: Dr. Rekha R. Warrier

Scientist-E, Institute of Forest Genetics and Tree Breeding (IFGTB),

P.B.No. 1061, R.S. Puram, Coimbatore-641002, Tamil Nadu, India

E-mail: rekhawarrier@gmail.com

Tel.: +91-9442918647; +91-4222484167
}

Copyright () 2019 Ukaaz Publications. All rights reserved.

Email: ukaaz@yahoo.com; Website: www.ukaazpublications.com amounts of plant growth regulators, mineral salts and carbon sources used, and environmental conditions, such as temperature, light, and gas composition in culture. The principal advantage of this technology is that it provides continuous, reliable source of pharmaceuticals. It could also be used for large-scale culture of plant cells from which these metabolites can be extracted. Production of many valuable secondary metabolites, namely; chlorogenic acid, taxoid, catharanthine and ginsenoside have been reported (Wang et al., 2003).

In traditional medicines, a large number of polyherbal formulations are used in the treatment of various chronic disease conditions (Nayanabhirama, 2016). These formulations have an appropriate cure against many diseases like jaundice, asthma, arthritis, diabetes, etc., where there is no complete cure in allopathy (Biradar, 2015; Subramoniam, 2016). However, quality assessment of herbal formulations is of paramount importance to justify their acceptability in modern system of medicine (Pushpangadan et al., 2018).

Aegle marmelos (L.) Corrêa is a sacred plant which belongs to the family Rutaceae. It is used in indigenous systems of medicine in India, China, Burma and Srilanka (Sivakumar et al., 2006). The bark of the roots finds use in the preparation of more than 75 medicinal formulations. Increasing demand of Ayurvedic medicines warrants more of plant material for preparations. Unscientific harvesting has resulted in a decline in this species in the wild. To check erosion of genetic stocks, and to ensure a continuous supply of the crude secondary metabolites, in vitro culture technology would enable production of these compounds in the callus or medium.

This paper focuses on the evaluation of the antimicrobial efficacy of the callus-derived tissues of A.marmelos. Efficacy was tested against phytopathogens, harmful and beneficial microbes and human pathogens, both bacteria and fungi (Figure 1). 


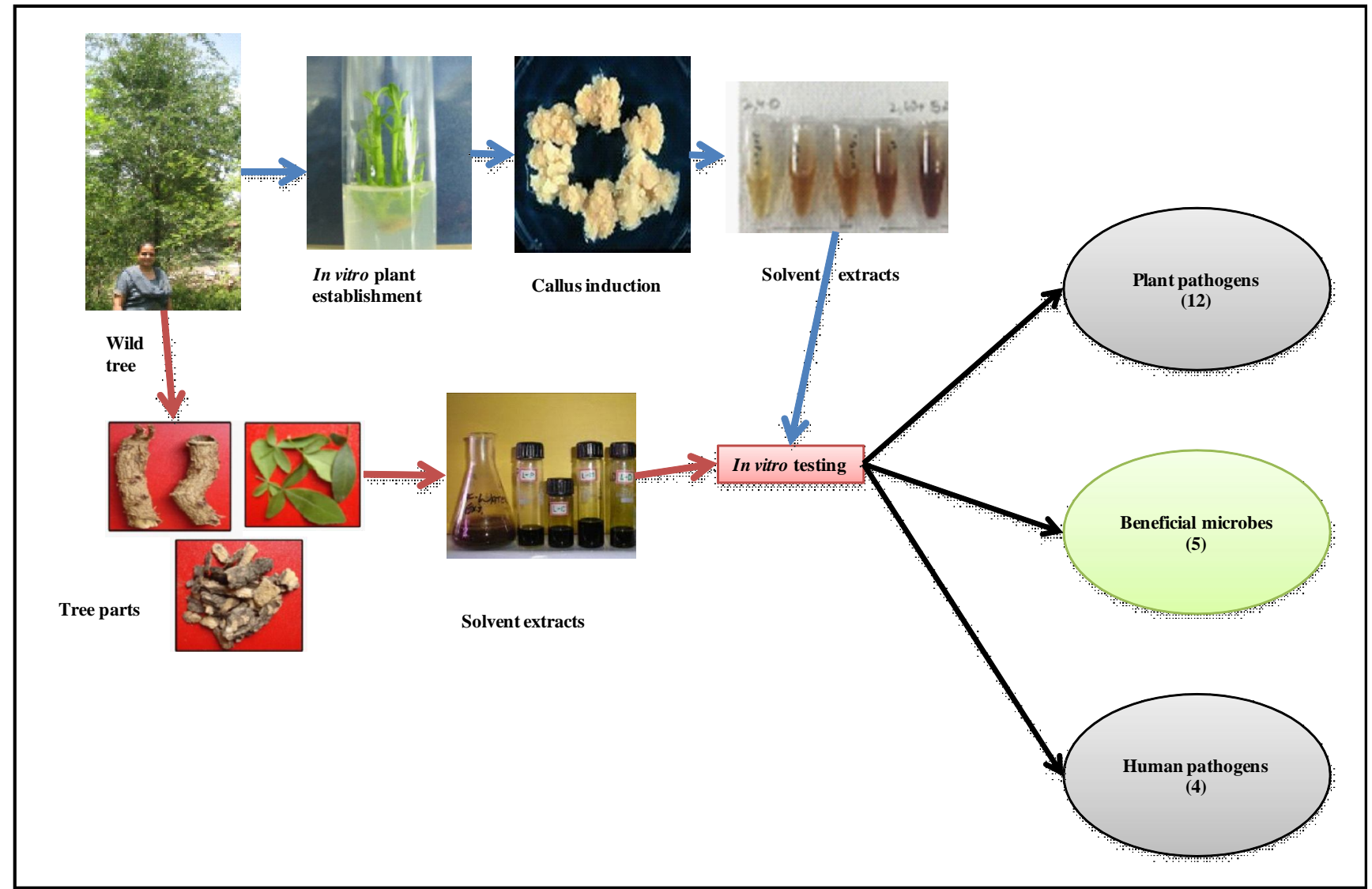

Figure 1: Flow chart illustrating the sequence of steps followed in the study.

\section{Materials and Methods}

\subsection{Materials}

Three types of organisms were selected for the study. They include phytopathogens, beneficial microorganisms and human pathogens. The test organisms were maintained on nutrient agar (Hi Media, India) at $4{ }^{\circ} \mathrm{C}$ and sub-cultured before use. A schematic illustration of the work is presented in Figure 1.

\subsection{Phytopathogens}

Eleven fungal cultures used in this study were obtained from Department of Plant Pathology, Tamil Nadu Agricultural University, Coimbatore. The selected fungal pathogens, their major hosts and the diseases caused are given in the Table 1 .

\subsection{Beneficial microorganisms}

Five beneficial microorganisms, commonly used for $\mathrm{N}_{2}$ fixation, phosphorus solubilization and biocontrol in various crops were selected. Among these, one is a fungus and four are bacteria. The beneficial microorganisms chosen for the study and their major functions in plant ecosystem are given in the Table 2.

\subsection{Human pathogens}

Five human pathogens were tested at Microbiological Laboratory, Coimbatore, an NABL accredited laboratory, as it was considered unsafe carrying out the experiments with contagious organisms under general lab conditions (Table 3).
Table 1: Pathogenic fungi taken for study

\begin{tabular}{|c|l|l|l|}
\hline S.No. & Plant pathogen used & Crop & Disease \\
\hline 1. & Rhizoctonia solani & Rice & Sheath blight \\
2. & Macrophomina phaseolina & Groundnut & Root rot \\
3. & Fusarium oxysporum & Cotton & Wilt \\
4. & Scleorotium rolfsii & Groundnut & Root rot \\
5. & Alternaria solani & Tomato & Early blight \\
6. & Alternaria helianthi & Sunflower & Leaf spot \\
7. & Botridiplodia spp. & Coconut & Bud rot \\
8. & Colletotricum falcatum & Sugarcane & Red rot \\
9. & Trichosporium spp. & Casuarina & Casuarina \\
10. & Aspergillus niger & Groundnut & Crown rot \\
11. & Pyricularia oryzae & Rice & Rice blast \\
\hline
\end{tabular}

Table 2: Beneficial microorganisms used in the study

\begin{tabular}{|c|l|l|}
\hline S.No. & Organism & Major function \\
\hline 1. & Trichoderma viride & Antagonist \\
2. & Azospirillum lipoferum & Nitrogen fixer \\
3. & $\begin{array}{l}\text { Bacillus megaterium } \\
\text { var. phosphaticum }\end{array}$ & Phosphorus solubilizer \\
4. & $\begin{array}{l}\text { Gluconoacetobacter } \\
\text { diazotrophicus }\end{array}$ & Nitrogen fixer \\
5. & Pseudomonas striata & Phosphorus solubilizer \\
6. & Bacillus subtilis & Phosphorus solubilizer \\
\hline
\end{tabular}


Table 3: Human pathogens used against the extracts of A. marmelos

\begin{tabular}{|c|c|c|c|}
\hline S.No. & Organism & Type & Infection caused \\
\hline 1. & Klebsiella sp. & Gram-negative & $\begin{array}{l}\text { Pneumonia, urinary tract } \\
\text { infections, septicemia, } \\
\text { and soft tissue infections }\end{array}$ \\
\hline 2. & $\begin{array}{l}\text { Escherichia } \\
\text { coli }\end{array}$ & Gram-negative & Stomach disorders \\
\hline 3. & $\begin{array}{l}\text { Streptococcus } \\
\text { pyogenes }\end{array}$ & Gram-positive & $\begin{array}{l}\text { Localised skin } \\
\text { infections }\end{array}$ \\
\hline 4. & $\begin{array}{l}\text { Salmonella } \\
\text { typhi }\end{array}$ & Gram-negative & Typhoid/Enteric fever \\
\hline
\end{tabular}

2.5 Preparation of plant extracts (roots, leaves and stem bark extracts of $A$. marmelos)

Three different tissues of A. marmelos (leaves, stem bark and root bark) were collected and washed thoroughly with running tap water, followed by rinsing twice with distilled water. It was shade dried for a week and finely powdered and stored in a dark place for further use. About $30 \mathrm{~g}$ of each tissue was immersed in $150 \mathrm{ml}$ of solvents with varying polarities, namely; chloroform, methanol, dichloromethane and petroleum ether separately (in the ratio 1:5) and kept overnight for digestion. The extract was filtered using Whatman No. 44 filter paper and concentrated using rotary vacuum evaporator to obtain dried extract, which was then stored under refrigerated condition.

Based on pilot studies, S. rolfsii and A. helianthi responded to methanol and chloroform extracts. These were selected for further studies.

\subsection{Preparation of callus extracts}

Different explants were tested under tissue culture conditions, using varying combinations of media and growth hormones. The combinations which produced the highest weight of callus was selected and used for the study. The processing of callus was similar to that of plant parts extracted.

\subsection{In vitro testing of extracts against phytopathogens}

To the PDA medium, $0.5,1.0,1.5,2.0$ per cent of chloroform and methanol extracts of roots and 1.5, 2.0, 2.5 per cent of chloroform and methanol extracts of callus obtained from roots was added. PDA without extracts served as control. A mycelial disc $(9 \mathrm{~mm})$ of test fungi taken from 3-5 days old culture was placed into each plate and incubated at $28^{\circ} \mathrm{C}$ ( 3 days for $S$. rolfsii and 5 days for A. helianthi). Clear zone of inhibition formed around wells were considered indicative of antimicrobial activity. The inhibitory activity was measured by calculating the area of inhibition zone.

The diameter of mycelial colony was measured after the incubation period and per cent inhibition was calculated using the formula (Vincent, 1927), Inhibition $(\%)=(C-T) / C \times 100$, where $\mathrm{C}$ and $\mathrm{T}$ were mycelial growth $(\mathrm{cm})$ of test microbe in control and treatments, respectively.

The experiment was repeated thrice and the average values were calculated for antimicrobial activity.

\subsection{Determination of minimum inhibitory concentration (MIC) for effective extracts}

Minimum inhibitory concentration was taken as the lowest concentration of extract that completely inhibited the bacterial growth, indicated by the lack of visual turbidity. Trichoderma viride was used as the test microorganism.

\subsection{Compatibility studies-effective plant and callus extracts versus beneficial microorganisms}

One day old (24 h) culture of actively growing beneficial organism was streaked on the medium impregenated with specific plant extract and suitable concentration and respective controls (without plant extracts). The plates were incubated for 2 to 5 days (depending on the growth of organisms) and observed. The plates were scored - for no growth ++ for very less growth, ++ for moderate growth and +++ for growth compared to control. MICs of plant extracts were used to fix the inhibitory concentrations. Growth pattern was studied with an intention to check whether they retain their original morphological characteristics.

\subsection{Evaluation of the effect of plant extracts on the growth rate and growth pattern of human pathogens}

All the test strains were maintained on nutrient agar slopes and were sub-cultured once in every two weeks. These bacteria served as test pathogens for antibacterial activity assay. Antibiogram was done by disc diffusion method using plant extracts. The test quantity of extracts was dissolved in distilled water since it did not affect the growth of microorganisms, in accordance with control experiments. The surfaces of media were inoculated with bacteria from a broth culture. High potency biodiscs were placed on the agar. After $24 \mathrm{~h}$ of incubation at $37^{\circ} \mathrm{C}$, the plates were examined and the diameters of the inhibition zones were measured to the nearest millimeter.

Standard antibiotics of ampicillin-10 $\mu /$ disc, kanamycin-30 $\mu /$ disc, nalidixic acid-30 $\mu /$ disc, were used as positive controls. After $24 \mathrm{~h}$ of incubation, diameter of the inhibition zone was recorded in $\mathrm{mm}$. Clear zone of inhibition formed around wells were considered indicative of antimicrobial activity. The experiment was repeated thrice and the average values were calculated for antibacterial activity.

\subsection{Statistical analysis}

All the data were analyzed by analysis of variance (ANOVA), followed by Duncan's Multiple Range Test to separate the treatment means at $p \leq 0.05$, using SPSS. Data are expressed as mean and variation as standard deviation $(\mathrm{SD})$.

\section{Results}

\subsection{Identification of effective extracts}

Among the twelve plant extracts studied for antimicrobial activity, only A. marmelos roots showed antimicrobial activity against $S$. rolfsii and A. helianthi. The roots extracted in methanol, chloroform and dichloromethane showed inhibition of mycelial growth of $S$. rolfsii and A. helianthi. The other plant extracts exhibited either nil or slight antimicrobial activity. Extracts which exhibited antimicrobial activity were taken up for further studies. 


\subsubsection{S. rolfsii}

The chloroform extract of $A$. marmelos roots showed maximum mycelial inhibition (100 per cent) (Figure 2). Chloroform extract of the callus also showed significant inhibition ( 93.4 per cent) of mycelial growth of $S$. rolfsii (Figure 3).

\subsubsection{A. helianthi}

Methanol extract of A. marmelos roots and callus checked mycelial growth of A.helianthi (Figures 4 and 5) (100 and 94.45 per cent, respectively).

\subsection{Minimum inhibitory concentration (MIC) for pathogens}

The effective root and callus extracts subjected to varying concentrations showed that MIC was 1.5 per cent in case of chloroform extract of A. marmelos roots against $S$. rolfsii, 2 per cent in case of methanol extract of roots against A.helianthi, 2.5 per cent in case of chloroform extract of root callus against $S$. rolfsii and 2.5 per cent in case of methanol extract of callus against $A$. helianthi (Table 4).

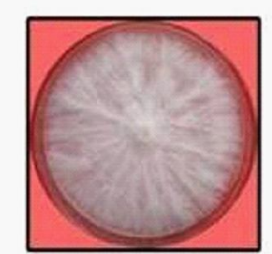

Control

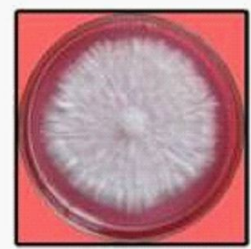

$0.5 \%(24.45 \%)$

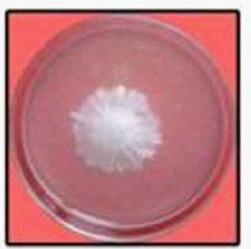

$1.0 \%(61.12 \%)$

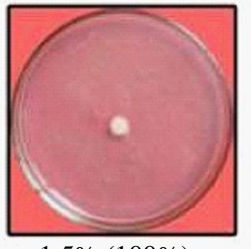

$1.5 \%(100 \%)$

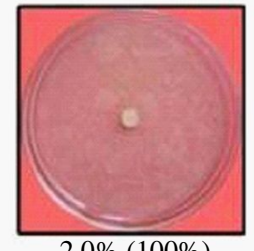

$2.0 \%(100 \%)$

Values in parentheses denote per cent inhibition

Figure 2: Effect of different concentrations of chloroform extract of A. marmelos root bark on $S$. rolfsii.

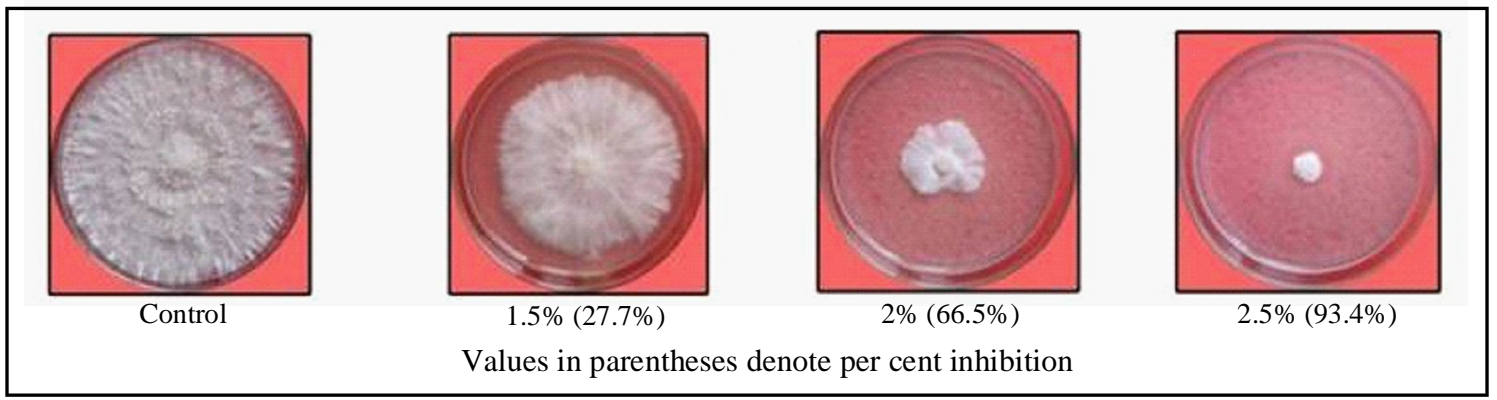

Figure 3: Effect of different concentrations of chloroform extract of A. marmelos callus on S. rolfsii.

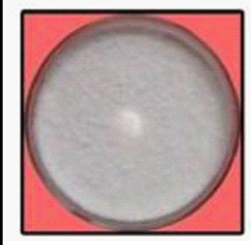

Control

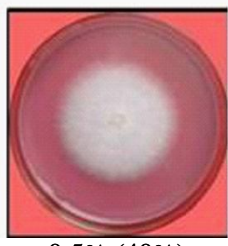

$0.5 \%(40 \%)$

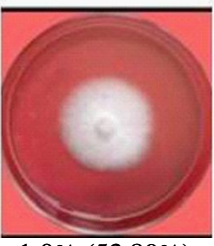

$1.0 \%(53.89 \%)$

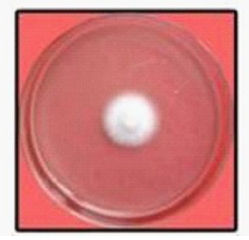

$1.5 \%(72.8 \%)$

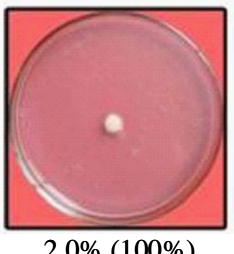

$2.0 \%(100 \%)$

Values in parentheses denote per cent inhibition

Figure 4: Effect of different concentrations of methanol extract of A. marmelos root bark on A. helianthi.

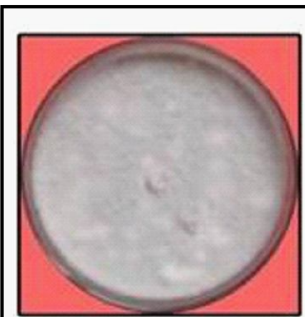

Control

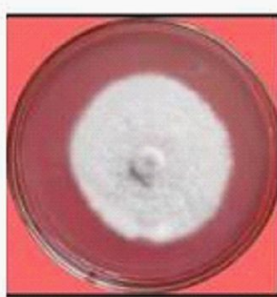

$1.5 \%(43.34 \%)$

Values in parentheses denote per cent inhibition

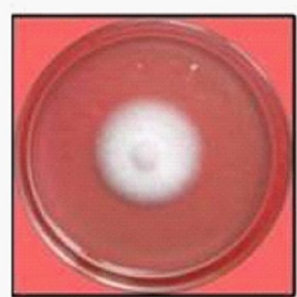

$2 \%(61.1 \%)$

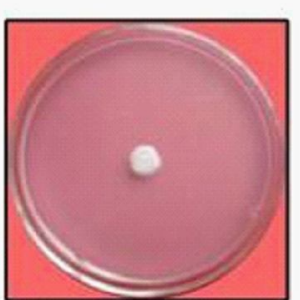

$2.5 \%(94.45 \%)$

Figure 5: Effect of different concentrations of methanol extract of A. marmelos callus on A. helianthi. 


\subsection{Compatibility studies - extracts versus beneficial microflora}

Both methanol and chloroform extracts of A. marmelos roots and callus were fully compatible with A.lipoferum, B.megaterium and B. subtilis and partially compatible with G. diazotrophicus, $P$. striata (Table 5). To evaluate the effect of plant extracts on the growth rate and growth pattern of beneficial organisms, colorimetric testing was done. No such deviation from normal growth was reported. All the colorimetric readings were found to be on par with each other. The plating tests conducted did not show any change in growth pattern of the tested organisms (Table 5).

\subsection{Compatibility of Trichoderma viride with effective root and callus extracts}

It was found that the methanol extracts of roots and callus was found to be fully compatible with $T$. viride and partially compatible with chloroform extracts of roots and callus (Table 6).

\subsection{Evaluation of the effect of plant extracts on the inhibition pattern of human pathogens}

\subsubsection{Escherichia coli}

Among all the effective extracts tested, methanol extract $(2.5 \%)$ of root bark showed maximum inhibition zone of E. coli $(12 \mathrm{~mm})$. The methanol extract of the callus showed an inhibition zone of $8.0 \mathrm{~mm}$ for the same organism.

\subsubsection{Klebsiella pneumonia}

Low concentrations of the methanolic extract showed inhibitory effect on $K$. pneumonia. Callus extract was observed to mimic the action similar to $2.0 \%$ extract.

\subsubsection{Salmonella typhi}

Among all the effective extracts tested, methanol extract of callus did not show a similar response to its inhibition.

Table 4: Testing of different concentrations of effective root and callus extracts of A.marmelos on pathogenic microbes ( $\mathrm{n}=3$ )

\begin{tabular}{|c|c|c|c|c|c|}
\hline Conc. $(\%)$ & Particulars & $\begin{array}{c}\text { AMR/ } \\
\text { Chloroform/ SR }\end{array}$ & $\begin{array}{c}\text { AMC/ } \\
\text { Chloroform/ SR }\end{array}$ & $\begin{array}{c}\text { AMR/ } \\
\text { Methanol/AH }\end{array}$ & $\begin{array}{c}\text { AMC/ } \\
\text { Methanol/AH }\end{array}$ \\
\hline \multirow[t]{2}{*}{0.0} & Colony dia. (mm) & 9.00 & 9.00 & 9.00 & 9.00 \\
\hline & $\%$ inhibition & 0.00 & 0.00 & 0.00 & 0.00 \\
\hline \multirow[t]{2}{*}{0.5} & Colony dia.(mm) & 6.80 & - & 5.40 & - \\
\hline & $\%$ inhibition & 24.45 & - & 40.00 & - \\
\hline \multirow[t]{2}{*}{1.0} & Colony dia. $\mathrm{mm}$ & 3.50 & - & 4.15 & - \\
\hline & $\%$ inhibition & 61.12 & - & 53.89 & - \\
\hline \multirow[t]{2}{*}{1.5} & Colony dia. mm & 0.00 & 6.35 & 2.45 & 5.10 \\
\hline & $\%$ inhibition & 100.00 & 27.70 & 72.80 & 43.34 \\
\hline \multirow[t]{2}{*}{2.0} & Colony dia.(mm) & 0.00 & 3.10 & 0.00 & 3.41 \\
\hline & $\%$ inhibition & 100.00 & 66.50 & 100.00 & 61.10 \\
\hline \multirow[t]{4}{*}{2.5} & Colony dia.(mm) & - & 0.60 & - & 0.50 \\
\hline & $\%$ inhibition & - & & - & \\
\hline & $\mathrm{SE}_{\mathrm{d}}$ & 0.12 & 0.12 & 0.11 & 0.11 \\
\hline & CD & 0.26 & 0.29 & 0.25 & 0.26 \\
\hline
\end{tabular}

*AMR : A. marmelos roots; SR : S.rolfsii; AH : A.helianthi *AMC : Aegle marmelos callus

Table 5: Compatibility studies and growth rate of beneficial bacteria with effective root extracts* $(n=3)$

\begin{tabular}{|c|c|c|c|c|c|c|c|}
\hline Name of the organism & $\mathbf{A M R} / \mathrm{C}$ & $\mathrm{AMC} / \mathrm{C}$ & $\mathbf{A M R} / \mathbf{M}$ & AMC/M & Control & $\mathbf{S E}_{\mathrm{d}}$ & $\mathrm{CD}(0.05)$ \\
\hline Azospirillum spp & $+++(0.14)$ & $+++(0.14)$ & $+++(0.12)$ & $++(0.12)$ & $+++(0.15)$ & 0.01 & 0.02 \\
\hline Gluconoacetobacter & $+++(0.36)$ & $+++(0.36)$ & $+++(0.38)$ & $++(0.39)$ & $+++(0.39)$ & 0.004 & 0.011 \\
\hline Bacillus megaterium var. phosphaticum & $+++(0.58)$ & $+++(0.58)$ & $+++(0.56)$ & $+++(0.56)$ & $+++(0.58)$ & 0.015 & 0.035 \\
\hline Pseudomonas striata & $+++(0.50)$ & $+++(0.50)$ & $+++(0.53)$ & $+++(0.54)$ & $+++(0.55)$ & 0.015 & 0.031 \\
\hline Bacillus subtilis & $++(0.44)$ & $++(0.44)$ & $++(0.45)$ & $++(0.45)$ & $+++(0.45)$ & 0.018 & 0.039 \\
\hline
\end{tabular}

++ Less than control;+++ Equivalent to control. *AMR : A.marmelos roots; *AMC : A.marmelos; C : Chloroform; M : Methanol. * MICs of effective root extracts taken for study 
Table 6: Compatibility testing of effective plant extracts* with Trichoderma viride $(\mathrm{n}=3)$

\begin{tabular}{|l|c|c|c|}
\hline Plant extract & Concentration $(\boldsymbol{\%})$ & Colony diameter $(\mathbf{m m})$ & Per cent inhibition \\
\hline Callus/chloroform & 2.0 & 8.15 & 9.45 \\
Callus/methanol & 2.5 & 8.65 & 3.89 \\
Root/methanol & 2.0 & 8.35 & 7.23 \\
Root/chloroform & 1.5 & 7.90 & 12.23 \\
Control & 0.0 & 9.00 & 0.00 \\
\hline
\end{tabular}

$\mathrm{SE}_{\mathrm{d}} 0.15, \mathrm{CD}(0.05) 0.38 *$ MICs of effective root extracts taken for study.

Table 7: Testing of different concentrations of effective root and callus extracts* of A. marmelos on human pathogens $(n=3)$

\begin{tabular}{|l|c|c|c|c|}
\hline \multirow{2}{*}{ Extracts } & \multicolumn{4}{|c|}{ Inhibition zone (mm) } \\
\cline { 2 - 5 } & $\boldsymbol{E}$. coli & K. pneumonia & S. typhi & S. pyogenes \\
\hline $1.5 \%$ Root Bark Methanol & $6 \pm 0.1$ & $11 \pm 0.1$ & $11 \pm 0.1$ & $6 \pm 0.05$ \\
$2.0 \%$ Root Bark Methanol & $6 \pm 0.1$ & $10 \pm 0.1$ & $11 \pm 0.1$ & $10 \pm 0.1$ \\
$2.5 \%$ Root Bark Methanol & $12 \pm 0.15$ & $7 \pm 0.05$ & $10 \pm 0.1$ & $7 \pm 0.05$ \\
$2.0 \%$ Callus - Methanol & $8 \pm 0.05$ & $9 \pm 0.1$ & $6 \pm 0.05$ & $7 \pm 0.05$ \\
Control\# & $28 \pm 0.05(\mathrm{~K})$ & $20 \pm 0.05(\mathrm{~A})$ & $20 \pm 0.05(\mathrm{Na})$ & $18 \pm 0.05(\mathrm{~A})$ \\
\hline
\end{tabular}

$\mathrm{SE}_{\mathrm{d}} 0.10, \mathrm{CD}(0.05) \quad 0.27 ; *$ MICs of effective root extracts taken for study;

\#A: Ampillicin; K:Kanamycin; Na:Naldixic acid

\subsubsection{Streptococcus pyogenes}

The methanol extract of the callus showed the same result as the $2.5 \%$ methanolic extract of the root bark. Both showed an inhibition zone of $7.0 \mathrm{~mm}$. The results have been presented in Table 7 .

\section{Discussion}

Synthesis of secondary metabolites on a commercial scale is not economically viable, because they often have complex quaternary structures essential for biological activity. Tree species being continuously exploited from the wild, these natural resources are becoming rare and even extinct. To overcome these bottlenecks, cell and tissue culture technology can be adopted for extraction of certain secondary metabolites (Rajendra and D' Souza, 2000). The cultured cells obtained from any part of the plant are expected to yield secondary metabolites similar to those of the plant grown in vivo under suitable culture conditions.

The capacity for plant cells to produce and accumulate many of the same valuable chemical compounds as the parent plant in nature has been well recognized. The rising demand for natural products has shifted focus on in vitro plants as potential factories for secondary phytochemical products (Karuppusamy, 2009).

Many workers have demonstrated the capability of in vitro induced callus to produce phytochemicals similar to the parent plant. Srividya et al. (1998) reported that the production of azadirachtin and nimbin was higher in cultured shoots and roots of Azadirachta indica, compared to field-grown plants. Examples of production of secondary metabolites from tree species include azadirachtin from Azadirachta indica (Sujanya et al., 2008); sennosides from Cassia senna (Shrivastava et al., 2006); podophyllotoxin from Podophyllum hexadrum (Chattopadhyay et al., 2002).
Studies hypothesize A.marmelos to have a broad spectrum antibacterial activity (Saradha Jyoti and Subba Rao, 2010). In the present study, about 90 per cent inhibition of mycelial growth of $S$. rolfsii and $A$. helianthi was shown by 1.5 per cent chloroform extract of A. marmelos roots and 2.0 per cent methanol extract of $A$. marmelos roots, respectively. A 2.5 per cent of chloroform / methanol extract of A. marmelos callus could inhibit the growth of $S$. rolfsii and A. helianthi, respectively. These results indicate that the callus contains some potent antimicrobial principles similar to the wild plants.

The study also tested the extracts against beneficial microbes used as biofertilizers and antagonists. Elslahi et al. (2014) reported that fungicides could be applied without restriction when using inocula based on growth promoting bacteria such as symbiotic nitrogen fixers (Rhizobium meliloti), non-symbiotic nitrogen fixers (Azospirillum braziliense) or potassium solibilizers (Bacillus circulans). Plant leaf extracts had little inhibitory effect on the mycelia growth of Trichoderma harzianum (Sharma and Chandel, 2016).

Several studies have revealed the antibacterial activity of $A$. marmelos (Dey and De, 2012; Gautam et al., 2013; Prasannabalaji et al., 2012). Aqueous and ethanol extracts of A. marmelos have been postulated to have strong inhibitory effect on the growth of some bacteria causing common human diseases including $S$. aureus, P. aeruginosa and E. coli (Chattopadhyay et al., 2009). Maity et al. (2009) have suggested A. marmelos to have therapeutic potential for developing novel antimicrobials. Antimicrobial potential of A.marmelos root extracts against E. coli, B. subtilis, $P$. aeruginosa, $S$. aureus, A. brasiliensis and $C$. albicans revealed high MIC, indicating the presence of wide range of phytochemicals like flavanoids, alkaloids, phenolic contents (Dahiya et al., 2016). Roots of A.marmelos contain coumarins such as scoparone, scopoletin, 
umbelliferone, marmesin and skimmianine, alkaloids, halopine and terpenes responsible for protective functions (Sharma and Dubey, 2016).

Sharma and Joshi (2011) reported that the active antioxidant compounds of A. marmelos are better extracted in methanol. Chloroform extract of the leaves of A. marmelos has been reported to have a higher activity against Proteus mirabilis and $K$. pneumoniae, whereas the methanol extracts have a better action against S. typhi (Kothari et al., 2011). The aqueous and ethanol extracts of A. marmelos have been shown to have significant antimicrobial activity against ten species of multidrug resistant strains of enteropathogenic bacteria (Rath and Padhy, 2012). Volatile oil obtained from the leaves of plant has been documented to have potent antifungal activity against various strains of fungi (Rana et al., 1997).

Methanol extract (2.5\%) of root bark and callus showed an inhibition of E.coli and S.pyogenes in the present study. The demonstration of inhibitory activity against both gram-positive and gram-negative bacteria is an indication of broad spectrum activity of these plant extracts which can be explored for drug development. Higher concentrations of callus extract inhibited K. pneumonia. S. typhi, though responded to wild plant extracts, was not inhibited by callus extracts. Petroleum ether extract obtained from callus culture of $A$. marmelos has been documented to have an inhibitory effect on the growth of $S$. typhi under in vitro conditions (Thangavel et al., 2008).

The efficacy of the metabolites produced under in vitro conditions have been tested. Ethanol extract of in vitro regenerated plantlets of Orthosiphon stamineus, showed strong scavenging activity with per cent inhibition higher than the wild plant extracts (Sheena and Jothi, 2015).

In vitro derived calli and calli mediated shootlet extract demonstrated significant antibacterial activity in Balisospermum montanum and Alternanthera sessilis (Johnson et al., 2005; 2010).

\section{Conclusion}

Based on the present study, it could be concluded that the extracts from A. marmelos roots possess strong fungitoxic and antibacterial properties. The ability of the plant extracts of A. marmelos to inhibit growth of bacteria and fungi is an indication of its broad spectrum antimicrobial activity which could be a potential source for development of novel antimicrobial agents (Meena et al., 2016). The callus extracts from A. marmelos possess strong biocidal properties as is evident from the antifungal and antibacterial activities presented in the study. These activities mimicked similar activities observed in the wild plants. The resultant extracts, thus obtained could replace wild plant parts, thereby enabling us to achieving our aim of conservation of the genetic resources. Further, studies are needed to test thermostability, stability to storage and phytotoxicity.

\section{Acknowledgements}

The authors gratefully acknowledge the financial assistance from National Medicinal Plants Board, GoI (R\&D/TN-01/2013-14).

\section{Conflict of interest}

The authors declare that no conflict of interest exists in the course of conducting this research. All authors had final decision regarding the manuscript and the decision to submit the findings for publication.

\section{References}

Biradar, D.P. (2015). Medicinal plants and phytomedicines. Ann. Phytomed., 4(1):1-5.

Chattopadhyay, R.R.; Bhattacharyya, S.K.; Medda, C.; Chanda, S. and Bag, A. (2009). A comparative evaluation of antibacterial potential of some plants used in Indian traditional medicine for the treatment of microbial infections. Braz. Arch. Biol. Technol., 52:1123-1128.

Chattopadhyay, S.; Farkya, S.; Srivastava, A.K. and Bisaria, V.S. (2002). Bioprocess considerations for production of secondary metabolites by plant cell suspension cultures. Biotechnol. Bioprocess. Eng., 7:138-149.

Dahiya, R.; Tomar, R.S. and Shrivastava, V. (2016). Evaluation of antimicrobial potential of Aegle marmelos root extract against selected microorganisms. Int. J. Pharm. Bio. Sci., 7(3):1175-1178.

Dey, A. and De, J.N. (2012). Ethnobotanical survey of Purulia district, West Bengal, India for medicinal plants used against gastrointestinal disorders. J. Ethnopharmacol., 143(1):68-80.

Dong, H.D. and Zhong, J.J. (2001). Significant improvement of taxane production in suspension cultures of Taxus chinensis by combining elicitation with sucrose feed. Biochem. Eng. J., 8:145-150.

Elslahi, R.H.; Osman, A.G.; Sherif, A.M. and Elhussein, A.A. (2014). Comparative study of the fungicide benomyl toxicity on some plant growth promoting bacteria and some fungi in pure cultures. Interdiscip. Toxicol., 7(1):12-16.

Gautam, M.K.; Ghatule, R.R.; Singh, A.; Purohit, V.; Gangwar, M.; Kumar, M. and Goel, R.K. (2013). Healing effects of Aegle marmelos (L.) Correa fruit extract on experimental colitis. Indian. J. Exp. Biol., 51(2): 157-164.

Johnson, M.; Berhanu, A. and Mulugeta, K. (2005). Regeneration from callus cultures of Rhinacanthus nasutus L. Kurtz. Eth. J. Sci. Technol., 3(1):17-24.

Johnson, M.; Wesely, E.G.; Selvan, N. and Kavitha, M.S. (2010). In vivo and in vitro antibacterial efficacy of Alternanthera sessilis (Linn.). Int. J. Pharm. Res. Dev., 2(10):72-79.

Kala, C.P.; Dhyani, P.P. and Sajwan, B.S. (2006). Developing the medicinal plants sector in northern India: Challenges and opportunities. J. Ethnobiol. Ethnomed., 2:1-15.

Karuppusamy, S. (2009). A review on trends in production of secondary metabolites from higher plants by in vitro tissue, organ and cell cultures. J. Med. Plants Res., 3:1222-1239.

Kothari, S.; Mishra, V.; Bharat, S. and Tonpay, S.D. (2011). Antimicrobial activity and phytochemical screening of serial extracts from leaves of Aegle marmelos (Linn.). Acta Pol. Pharm., 68(5):687-692.

Maity, P.; Hansda, D.; Bandyopadhyay, U. and Mishra, D.K. (2009). Biological activities of crude extracts and chemical constituents of bael, Aegle marmelos (L.) Corr. Indian. J. Exp. Biol., 47(11):849-861.

Manoharachary, C. and Nagaraju, D. (2016). Medicinal plants for human health and welfare. Ann. Phytomed., 5(1):24-34.

Meena, R.K.; Pareek, A. and Meena, R.R. (2016). Antimicrobial activity of Aegle marmelos (Rutaceae) plant extracts. Int. J. MediPharm. Res., 2(1):1-5.

Nayanabhirama, Udupa. (2016). Status on herbal drugs and their future perspectives. Ann. Phytomed., 5(1):1-3.

Prasannabalaji, N.; Muralitharan, G.; Sivanandan, R.N.; Kumaran, S. and Pugazhvendan, S.R. (2012). Antibacterial activities of some Indian traditional plant extracts. Asian Pac. J. Trop. Dis., 2:S291-295. 
Pushpangadan, P.; George, V.; Ijinu, T.P. and and Chithra, M.A. (2018). All India coordinated research project on ethnobiology and genesis of ethnopharmacology research in India including benefit sharing. Ann. Phytomed., 7(1):5-12.

Rajendra, K. and D'Souza, L. (2000). Secondary metabolite of Ayurvedic plants in vitro. In: Plant biotechnology-recent advances (ed Trivedi, P.C.), I Ed. Panima Publishing Corporation, New Delhi. pp:350-358.

Rana, B.K.; Singh, U.P. and Taneja, V. (1997). Antifungal activity and kinetics of inhibition by essential oil isolated from leaves of Aegle marmelos. J. Ethnopharmacol., 57:29-34.

Rath, S. and Padhy, R.N. (2012). Surveillance of multidrug resistance of 10 enteropathogens in a teaching hospital and in vitro efficacy of 25 ethnomedicinal plants used by an Indian aborigine. Asian Pac. J. Trop. Dis., 2:336-346.

Saradha Jyothi, K. and Subba Rao, B. (2010). Antibacterial activity of extracts from Aegle marmelos against standard pathogenic bacterial strains. Int. J. PharmTech. Res., 2(3):1824-1826.

Sharma, M. and Joshi, S. (2011). Comparison of antioxidant activity of Andrographis paniculata and Tinospora cordifolia leaves. J. Curr. Chem. Pharm. Sci., 1(1):1-8.

Sharma, M. and Chandel, S. (2016). In vitro evaluation of compatibility of indigenous Trichoderma harzianum with botanicals. Int. J. Sci. Env. Tech., 5(3):1131-1136.

Sharma, N. and Dubey, W. (2016). Bioactive compounds present in Aegle marmelos and their role in medicinal properties: A review. Int. J. Pharm. Bio. Sci., 7(3):170-176.
Sheena, E.V. and Jothi, G.J. (2015). Comparative phytochemical screening and antioxidant properties of in vitro and in vivo propagated Orthosiphon stamineus Benth (Lamiaceae). Asian. J. Pharm. Clin. Res., 8(4):216-220.

Shrivastava, N.; Patel, T. and Srivastava, A. (2006). Biosynthetic potential of in vitro grown callus cells of Cassia senna L. var. senna. Curr. Sci., 90(11):1472-1473.

Sivakumar, V.; Warrier, R.R.; Anandalakshmi, R.; Parimalam, R.; Vijaya Chandaran, S.N. and Gurudev Singh, B. (2006). Seed storage studies in Aegle marmelos and Feronia elephantum. Ind. For., 132(4):502506 .

Srividya, N.; Sridevi, B.P. and Satyanarayana, P. (1998). Azadirachtin and nimbin content in in vitro cultured shoots and roots of Azadirachta indica A. Juss. Ind. J. Plant Physiol., 3(2):129-134.

Subramoniam, A. (2016). Food from plants with antiarthritic properties. Ann. Phytomed., 5(1):4-23.

Sujanya, S.; Poornasri, D.B. and Sai, I. (2008). In vitro production of azadirachtin from cell suspension cultures of Azadirachta indica. Biosci. J., 33:113-120.

Thangavel, K.; Sasikala, M. and Maridass, M. (2008). In vitro antibacterial potential of Aegle marmelos (L.) callus extract. PhOL., 3:190196.

Wang, H.Q.; Yu, J.T. and Zhong, J.J. (2000). Significant improvement of taxane production in suspension cultures of Taxus chinensis by sucrose feeding strategy. Process Biochem., 35:479-483.

Citation: Priyadharshini, P.; Ashok Raj and Rekha R. Warrier (2019). Phytochemical and antimicrobial efficacy of in vivo and in vitro tissues of Aegle marmelos (L.) Corrêa. Ann. Phytomed., 8(1):140-147. 